\title{
Outcome of induction of labour with dinoprostone at a teaching hospital in Nepal
}

\author{
Punita Yadav $^{1 *}$, Veena R. Shrivastava ${ }^{2}$
}

${ }^{1}$ Senior Resident, Obstetrics and Gyanecology, B.P. Koirala Institute of Health Science, Dharan, Nepal ${ }^{2}$ Department of Obstetrics and Gynecology, Nepal Medical College Teaching Hospital, Attarkhel, Kathmandu, Nepal

Received: 04 January 2017

Revised: 07 February 2017

Accepted: 27 February 2017

\section{*Correspondence:}

Dr. Punita Yadav,

E-mail: punita_yadav@hotmail.com

Copyright: (C) the author(s), publisher and licensee Medip Academy. This is an open-access article distributed under the terms of the Creative Commons Attribution Non-Commercial License, which permits unrestricted non-commercial use, distribution, and reproduction in any medium, provided the original work is properly cited.

\section{ABSTRACT}

Background: Induction of labour has now become a common practice; this study was conducted to find the outcome of induction of labour in pregnant women in relation to: induction delivery interval, mode of delivery, maternal complications and fetal outcome.

Methods: It was a hospital based prospective study conducted from April 2012 to March 2013. Singleton pregnancy of gestational age $\geq 37$ weeks, with vertex presentation and Bishops Score $<6$ were the cases included for induction. Dinoprostone $(0.5 \mathrm{mg})$ intracervically was used for induction. The different outcome parameters were analyzed.

Results: Of 100 cases enrolled, majority 93\% were below 30 years, mean gestational age of induction was $40.7 \pm$ 0.7 weeks and $58 \%$ were primi gravida. Ante natal care visit of $\geq 3$ was present only in $66 \%$. At induction $55 \%$ had bishop score of (0-3) and rest had score of (4-5). Postdated pregnancy (67\%) followed by hypertension (13\%) were the two most common causes for induction. 58\% required second dose of dinoprostone, and the induction delivery interval was $24.3 \pm 9.6 \mathrm{hrs}$. $63 \%$ of the induced labour progress for vaginal delivery. Fetal distress $(56.4 \%)$ was the commonest indication for caesarean section (CS). $6 \%$ of the cases had postpartum hemorrhage. $13 \%$ of the delivered neonate required NICU care, of which $53.8 \%$ was moderately asphyxiated. There was no maternal or neonatal death. Conclusions: In pregnancy undergoing induction of labour, CS is not uncommon, and there are few chances of maternal and neonatal morbidities. Therefore, obstetrician should be vigilant to avoid any untoward events.

Keywords: Delivery, Dinoprostone, Induction, Labour, Neonates, Outcome

\section{INTRODUCTION}

Induction of labour (IOL) means initiation of uterine contractions (after period of viability) by any method (medical, surgical or combined) for the purpose of vaginal delivery. ${ }^{1}$ Induction is indicated; when benefits to either the mother or fetus outweigh those of continuing the pregnancy. ${ }^{2}$ Indication of induction include post-dated pregnancy, maternal disease (e.g. diabetes mellitus, renal disease, and hypertension), intrauterine growth retardation, logistic reasons and other medical or obstetric conditions. The most common indication for labor induction is post-dated pregnancy. ${ }^{3}$ According to the most current studies, the rate of induction varies from $9.5 \%$ to $33.7 \%$ of all pregnancies annually. ${ }^{4}$ Approximately $20 \%$ of all pregnant women require medical intervention to induce labor. ${ }^{5}$

Among different Prostaglandins (PGs) available in the market, Dinoprostone gel ( $\left.\mathrm{PGE}_{2}\right)$ and Misoprostol $\left(\mathrm{PGE}_{1}\right)$ show safety and efficacy in the induction of labour. $\mathrm{PGE}_{2}$ has been successfully used from early 1970s for cervical ripening and induction of labour but became popular since 1986. Misoprostol came into use for IOL in 1991. When Bishop Score is favourable $(\mathrm{BS}>6)$, the preferred pharmacologic agent has been oxytocin in gradual 
escalating doses. ${ }^{6}$ We used dinoprostone gel for induction in this study.

\section{METHODS}

This study was a hospital based prospective analytical study, conducted in obstetrics ward of Nepal Medical College and Teaching Hospital (NMCTH), Kathmandu, Nepal. The study was done on cases undergoing induction of labour at obstetrics ward, with due approval from ethical committee of Nepal medical college teaching hospital, Kathmandu, Nepal. Written consent from pregnant ladies was taken before the study. Inclusion criteria: Live singleton pregnancy of gestational age more than or equal to 37 weeks, Vertex presentation and Bishop score $<6$. Exclusion criteria: Previous cesarean section or scarred uterus, non-vertex presentation, parity more than or equal to 4, multiple gestations, contraindications to prostaglandin. Medical disorders like heart disease, asthma. Patients with ante partum hemorrhage, pre-mature rupture of membrane and fetal anomaly. According to previous year hospital data the rate of induction of labour was approximately $10 \%$ of total deliveries per year. Among all induced cases around $3.3 \%$ fulfilled the inclusion criteria. So to complete the study within the period of 1 year a total number of 100 cases were chosen. The study was conducted for one year (from April 2012 to March 2013).

In women who met the inclusion criteria Dinoprostone gel $(0.5 \mathrm{mg})$ was inserted intracervically at $6 \mathrm{am}$. The patient was advised to lie in the left lateral position for 60 min after instillation. Fetal Heart Sound (FHS) and uterine contraction was monitored in every $15 \mathrm{~min}$ for 1hrs. After $1 \mathrm{hr}$ patient was shifted to ante-natal ward where FHS and uterine contraction was monitored in every $1 \mathrm{hr}$ for $6 \mathrm{hrs}$. After six hour patient was reexamined and the Bishop score was again determined. If the score was less than 6, next dose of dinoprostone gel was kept intracervically as before. Monitoring of FHS and uterine contraction was done, every $15 \mathrm{~min}$ for $1 \mathrm{hr}$ then after every $1 \mathrm{hr}$ until further intervention was done. Oxytocin infusion was started next day at $6 \mathrm{am}$, in those cases who didn't deliver by then, irrespective of bishop score. According to hospital protocol, 5 units syntocinon in $500 \mathrm{ml} \mathrm{RL}$ was given at rate of $10 \mathrm{drops} / \mathrm{min}$ and escalated by 10 drops per min every half an hour until maximum of 40 drop per min. Total two pints RL with oxytocin was given and if patient failed to reach active stage of labour then cesarean section was performed for failed induction as per the protocol.

Artificial rupture of membrane (ARM) was done routinely after the patient enters into active stage of labour. Fetal heart sound was monitored at an interval of $30 \mathrm{~min}$ in active stage and $5 \mathrm{~min}$ in $2^{\text {nd }}$ stage of labour. All cases were closely observed till delivery. Mode of delivery, complication to mother or fetus during delivery, apgar score of baby at $1 \& 5 \mathrm{~min}$, birth wt of baby, sex of baby was noted. All mothers and babies were followed till discharge and complication if any was noted.

The particulars of the patient like Last Menstrual Period (LMP), Expected Date of Delivery (EDD), indication of induction of labour, time of induction, doses of dinoprostone, Oxytocin induction and augmentation, ARM, duration of labour, induction delivery interval (IDI), mode of delivery, babies weight, sex and apgar score at 1 and $5 \mathrm{~min}$ were noted into a structured questionnaire.

Data was entered in Microsoft Excel and analyzed on SPSS statistical package 20. Descriptive statistics like mean, median, range, standard deviation was calculated as required.

\section{RESULTS}

There were 2183 total deliveries conducted in NMCTH during our study period. 1522 cases had normal delivery and 661 cases had abnormal delivery. About $10 \%$ of the cases were induced, out of which 100 cases were enrolled in the study. The mean age of cases enrolled was $24.6 \pm 3.8$ yrs, majority $93 \%$ were below 30 years. While $12 \%$ were below 20 yrs and $2 \%$ were above $35 \%$ (in the high risk group). $58 \%$ of pregnancy was primi gravida, with sufficient antenatal checkups of $\geq 3$ was done only by $66 \%$. This justifies the lack of awareness among pregnant female to do regular checkups. Mean gestational age at induction was 40.7 weeks \pm 0.7 weeks. All cases undergoing induction were at term gestation, however $91 \%$ were post-dated. At induction $55 \%$ had bishop score of (0-3) and rest had score of (4-5).

The reasons for induction in our study are depicted in the Table 1. Post-dated pregnancy $(67 \%)$ followed by hypertension $(13 \%)$ were the two most common causes for induction.

Table 1: The common indications for induction.

\begin{tabular}{|lll|}
\hline Indication for induction & N & $\%$ \\
\hline Decreased fetal movement & 9 & 9 \\
\hline Post dated & 67 & 67 \\
\hline Pregnancy induced hypertension (PIH) & 13 & 13 \\
\hline Diabetes Mellitus & 1 & 1 \\
\hline Niggling Pain & 2 & 2 \\
\hline Rh negative mother & 5 & 5 \\
\hline Oligohydroamnios-IUGR & 2 & 2 \\
\hline Previous Neonatal death & 1 & 1 \\
\hline
\end{tabular}

The percentage of pregnant requiring second dose of dinoprostone was 58\%. Oxytocin was use for augmentation in $68 \%$ of the cases. Among the induced cases $63 \%$ normally progressed for vaginal delivery and the remaining underwent caesarean section. The mean of induction delivery interval was $(24.3 \pm 9.6 \mathrm{SD}) \mathrm{hrs}$. 
The indications for caesarean section are elicited in table 2. Fetal distress $56.4 \%$, followed by followed by failed induction and prolonged 2nd stage of labor (16.21\%) each were the most common indications for CS. $78.3 \%$ of those undergoing CS were nullipara.

Table 2: Indications for caesarean section.

\begin{tabular}{|llll|}
\hline CS indication & Frequency (n) & $(\%)$ \\
\hline Fetal distress & & 19 & 51.35 \\
\hline $\begin{array}{l}\text { Failed } \\
\text { induction }\end{array}$ & Nullipara & 5 & 16.21 \\
\cline { 2 - 4 } & Multipara & 1 & 16.21 \\
\hline Prolonged II stage of labor & 6 & 10.81 \\
\hline Non progress of labor & 4 & 5.40 \\
\hline CPD & 2 & 100.0 \\
\hline Total & 37 & \\
\hline
\end{tabular}

Among the complications in mother $6 \%$ of the induced cases had postpartum hemorrhage. No other complications were observed in mother. The APGAR score of the neonate at $1 \mathrm{~min}$ and $5 \mathrm{~min}$ of life is depicted in the bar graph Figure 1.

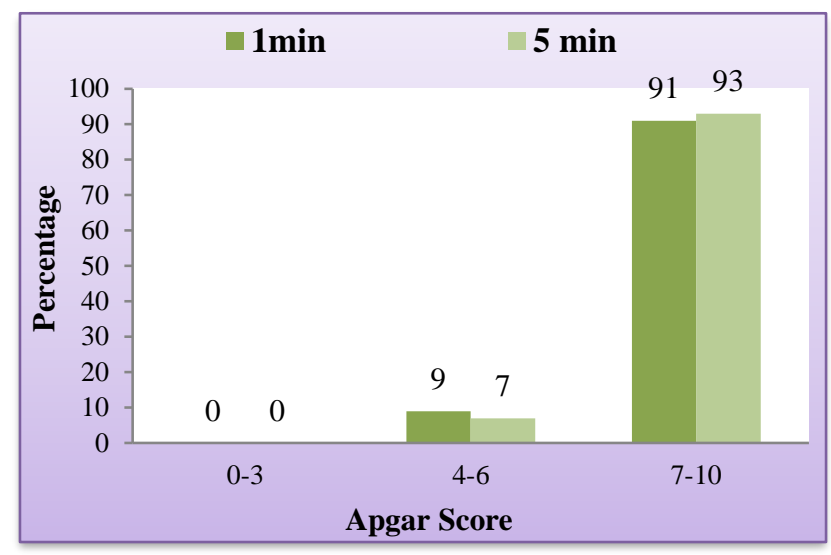

$13 \%$ of the cases required NICU care of which 7 cases were moderately asphyxiated with APGAR score (4-6) at 5 mins of life Figure 1, followed by respiratory distress in 3 cases. Neonatal seizure and IUGR were others among admitted cases.

\section{DISCUSSION}

Broadly the indications for IOL can be classified as fetal, maternal or both. Among these, fetal reasons constitute the majority. Sometime social cause like fear of poor perinatal outcome is often an important factor. In our study, the major indication for induction was postdated pregnancy $(69.9 \%)$, followed by maternal hypertension (HTN) (13.6\%) and decrease fetal movement $(8.9 \%)$. According to secondary analysis of the WHO global survey of maternal and newborn health of 2004 and 2005, done in Africa, the pre-labor rupture of membranes was the commonest indication for induction of labor $(20.8 \%)$ followed by post-dated pregnancy $(11.5 \%){ }^{7}$ In a Finnish study, hypertensive disorder of pregnancy $(40 \%)$ was the most common indication followed by post-dated pregnancy $(27.5 \%)$, intra-uterine growth retardation $(11.5 \%)$, fetal deaths $(5 \%)$ and others. ${ }^{8}$ But, in an Indian study, the indications were mainly post-term pregnancy (72\%) followed by hypertension $(25 \%) .{ }^{9}$ This might be due to the practice of early induction at 41 weeks in our institute whereas in WHO survey $42 \mathrm{wks}$ was taken as postdated and we also have excluded cases with PROM.

In the present study, the overall failed induction rate was $16.21 \%$. Parity showed a strong relation to the success of induction. Most of the failed induction cases $(83.3 \%)$ were nullipara. In a Singaporean study, overall failed induction rate was $7 \%$ in patients induced with amniotomy and syntocinon. ${ }^{10}$

In our study IDI in nulliparous women was longer than multiparous women. Similarly, Mukherjee and his colleagues reported the mean IDI, in women with the BS of less than 5 , to be $22.5 \mathrm{hrs}$ and $12.4 \mathrm{hrs}$ in primigravida and multigravida respectively. ${ }^{9}$ In addition, Mishra and her colleagues also found mean IDI to be $11.35 \mathrm{hrs}$ in primigravida and $7.99 \mathrm{hrs}$ in multigravida, all of them had a pre-induction BS of less than 3. ${ }^{11}$ All these findings supports that IDI is longer in nulliparous.

In our study $37 \%$ of induced cases underwent CS of which $78.3 \%$ were nullipara. Misra et al in a study of induced labour with a modified BS of $0-3$, reported the CS rate of $47.2 \%$ and $14.6 \%$ in primigravida and multigravida respectively. ${ }^{11}$ In a study by Xenakis et al, maternal complications associated with induction were infrequent. Chorio-amnionitis was the most common complication occurring in 3.5\% .All other complications (hyper stimulation, $\mathrm{PPH}$, hysterectomy) occurred in $2 \%$ or less population. Overall $93 \%$ of the women experienced no complication. ${ }^{8}$ In our study PPH was only in $6 \%$.

The fetal/neonatal outcome in induced labour was generally good with no stillbirth or early neonatal deaths. The majority did not need NICU admission. Macer JA et al in their study found that all babies were born alive and there were no neonatal deaths in the induction group. Neonatal intensive care unit admission was only in $0.8 \%$ babies. ${ }^{13}$ In another study there was only $4.7 \%$ neonates were admitted to the NICU. ${ }^{10}$ More number $(13 \%)$ of NICU admission could be because of our hospital provision to keep even moderately asphyxiated child in NICU for observation for at least $24 \mathrm{hrs}$.

\section{CONCLUSION}

There are high chances of CS post induction, mostly in primigravida and sometime PPH could occur with few possibilities of neonatal depression. Hence all obstetricians should be very vigilant and anticipate complications beforehand. Similarly pediatrician should be alerted about the delivery conducted by induction. 
This can defer undue maternal and neonatal morbidity and mortality.

\section{ACKNOWLEDGEMENTS}

Authors would like to acknowledge Dr. Amrita Giri for guidance and Dr. Shankar Prasad Yadav for helping with statistics.

\section{Funding: No funding sources}

Conflict of interest: None declared

Ethical approval: The study was approved by the Institutional Ethics Committee

\section{REFERENCES}

1. Dutta DC. Induction of labour. Text book of obstetrics. 7th ed. Kolkota (India): New central Book Agency (P) Ltd; 2010:522-31.

2. Cunnigham FG, Leveno KJ, Bloom SL, Hauth JC, Rouse DJ, Spong CY. Labour induction, Williams Obstetrics. 23rd ed. McGraw Hill; 2010:500-10.

3. Gupta N, Mishra SL, Jain S.A randomized clinical trial comparing Misoprostol and Dinoprostone for cervical ripening and labour induction. J Obstet Gynecol India. 2006;62(2):149-51.

4. Tenore JL. Methods for cervical ripening and induction of labour. Am Fam Physician. 2003;67(48):2123-8.

5. Castanteda C.S.Misoprostol dose selection in a controlled-release vaginal insert for induction of labor in nulliparous women. Am J Obstet Gynecol. 2005;193:1071-5.

6. Agrawal P. Cervical ripening and induction of lobour. Obstet Gynecol. 2003;3:113-5.

7. Bukola F, Idi N, M'Mimunya M, Jean-Jose WM, Kidza M, Isilda $\mathrm{N}$ et al. Unmet need for induction of labor in Africa: secondary analysis from the 2004 2005 WHO global maternal and perinatal health survey (a cross-sectional survey). BMC Public Health. 2012 Aug $31 ; 12: 722$.

8. Park KH, Hong JS, Shin DM, Kang WS. Prediction of failed labor induction in parous women at term: role of previous obstretic history, digital examination and sonographic measurement of cervical length. J Obstet Gynaecol Res. 2009;35(2):301-6.

9. Mukherjee K, Neogi U, Gangooli G, Mishra R, Verma M, Dayal M et al. A comparative study of induction of labour by prostagladin E2 and oxytocin and its outcome. J Obstet Gynaecol India. 1996;46:631-5.

10. Jarvelin MR, Hartikainen-Sorri AL, Rantakallio P. Labour induction policy in hospital of different levels of specialisation. $\mathrm{Br} \mathrm{J}$ Obstet Gynaecol. 1993;100:310-5.

11. Misra M, Vavre S. Labour induction with intracervical prostagladin gel and intravenous oxytocin in women with a very unfavourable cervix. Australia New Zealand J Obstet Gynaecol. 1994;34:511-5.

12. Xenakis EMJ, Piper JM, Conway DL, Longer O. Induction of labor in the nineties: Conquering the unfavourable cervix. Obstet Gynaecol. 1997;90(2)235-9.

13. Macer JA, Macer CL, Chan LS. Elective induction versus spontaneous labour: A retrospective study of complications and outcome. Am J Obstet Gynaecol. 1992;166(6):1690-7.

Cite this article as: Yadav $\mathrm{P}$, Shrivastava VR. Outcome of induction of labour with dinoprostone at a teaching hospital in Nepal. Int J Reprod Contracept Obstet Gynecol 2017;6:1170-3. 